\title{
Improvement of Work Ability by Exercise Program
}

\author{
Joongil Shin ${ }^{1}$, Sujong Park ${ }^{2)}$, Dongjoo Yang $^{3)}$, Soohee Park ${ }^{4)}$, Yeongae Yang ${ }^{5)}$ \\ 1) Department of Occupational Therapy, Choonhae College of Health Sciences \\ 2) Department of Occupational Therapy, Daegu Health College \\ 3) Korea Safety Culture Civil Solidarity \\ 4) Department of Occupational Therapy, Health Science College, Honam University \\ 5) Department of Occupational Therapy, College of Biomedical Sciences and Engineering, Inje \\ University: 607 Obang-dong, Gimhae, Gyeongnam 621-749, Republic of Korea. TEL: +82 55-320- \\ 3686,FAX:+82 55-326-4885,E-mail: kanunu@hanmail.net
}

\begin{abstract}
Purpose] The purpose of this study was to investigate the effect of a worker's exercise program on work ability. [Subjects] The program was tested on 100 workers at 2 workplaces in Seoul. [Methods] Initially, we conducted a pre-test evaluation of the Worker's cardio-muscular endurance, muscular strength, muscular endurance, flexibility, body composition analysis and WAI. Then, the program was applied to the workers for 2 months. After the program had been applied, their post-test conditions were evaluated. The obtained data were analyzed by correlation analysis using a statistical software application (SPSS for Window 13.0). [Results] As a result of this study, we can see how a worker's exercise program is associated with work ability. There were statistically significant differences in work ability $(\mathrm{p}<0.01)$. [Conclusion] In conclusion, a worker's exercise program increased work ability. This suggest that it is important to manage on-going work ability through a prescribed exercise program. Key words: Exercise program, Work ability, Work Ability Index (WAI)
\end{abstract}

(This article was submitted May 1, 2012, and was accepted Jun. 15, 2012)

\section{INTRODUCTION}

A workman's work ability is directly related to productivity. Therefore, all around the world, it is an important task to find a method to increase work ability ${ }^{1)}$. Work ability is a person's ability to do work in his working life ${ }^{2)}$. In other words, the concept of work ability is defined as the ability of a worker to do his job, taking into account the specific work demands, the individual's health status, mental resources and work life ${ }^{3)}$.

Work ability may be influenced by time, location and population ${ }^{4)}$. Increasing work ability decreases work disability and prevents premature retirement ${ }^{5)}$. Therefore, it is essential to develop strategies that will increase work ability ${ }^{6}$. WAI (Work Ability Index) exists as a tool to evaluate work ability. The test used to determine WAI evaluates 4 areas. These areas are "job demands and environment", "work organization and work community", "professional competence", and "life style"7).

Stamina can be described as a physical as well as mental trait. Physical stamina is considered to be one of several fitness components used to evaluate health and fitness levels. Physical stamina levels can be increased through physical activity. There are many studies that point to physical activities being of help in easing heart disease, hypertension, stroke, diabetes mellitus, osteoporosis, depression and anxiety and similar chronic diseases ${ }^{8}$. Physical activity is a great help in saving medical costs ${ }^{9}$. Health promotion programs are underway at many work sites ${ }^{10)}$. However, there are too few studies that have examined the relationship between physical activity and work ability.

The objective of this study was to evaluate the improvement of work ability due to a workman's exercise program. Based on the results of this study, a systematic exercise program for workmen was developed and the foundation for future work was established. This will helps to increase work ability.

\section{SUBJECTS AND METHODS}

During the 197-day period from March 31st to October 13th, 2009, 100 workers from 2 work places in the Seoul area responded to an anonymous survey (Table 1).

Before the study, the principal investigator explained all procedures to the subjects in detail. All subjects signed an informed consent form, which was approved by the Inje University College of Human Health Science Studies Committee.

Physical stamina is the ability to perform intense work over a prolonged period of time. Physical body condition and work ability were evaluated by several tools. The examination of physical stamina called for the use of tools to measure (1) cardio-muscular endurance, (2) muscular strength, (3) muscular endurance, (4) flexibility and (5) body composition.

The gauging of work ability involved the Work Ability Index (WAI) tool. The index is determined on the basis of the answers to a series of questions that take into consider- 
Table 1. General characteristics of survey participants

\begin{tabular}{llll}
\hline Category & & & \\
\hline Gender & Male & 60 people & $60.0 \%$ \\
& Female & 40 people & $40.0 \%$ \\
Age & Below 45 & 50 people & $50.0 \%$ \\
& 45 and up & 50 people & $50.0 \%$ \\
Occupation & Workers & 26 people & $26.0 \%$ \\
& Service employees & 38 people & $38.0 \%$ \\
& Managers & 36 people & $36.0 \%$ \\
\hline Total & & 100 & $100.0 \%$ \\
\hline
\end{tabular}

ation the demands of work, the worker's health status and resources. The worker completes the questionnaire before an interview with an occupational health professional who rates the responses according to the instructions. WAI is a summary measure of seven items. The seven items are current work ability compared with the lifetime best, work ability in relation to the demands of the job, number of current diseases diagnosed by a physician, estimated work impairment due to diseases, sick leave during the past year (12 months), own prognosis for work ability 2 years from now and mental resources.

All subjects were evaluated by the above tools in the pre-test phase. Subsequently, each subject had to begin an exercise program that served as an intervention program over the next two months. An exercise program was prescribed for each individual subject based on the pre-test results evaluated by experts. The post-test evaluation was carried out one month after the invention program finished. We allowed an evaluation interval of three months so that the post-test outcome would not be affected by the pre-test results ${ }^{7)}$.

The collected data were analyzed using SPSS for Windows for frequency and correlation.

\section{RESULTS}

The general characteristics of the participants are shown in Table 1. The participants were 60 males $(60.0 \%)$ and 40 females $(40.0 \%)$. By age group, $50(50.0 \%)$ were under 45 years of age, and $50(50.0 \%)$ were 45 or over. By occupational rank, 26 were workers $(26.0 \%), 38$ were service employees (38.0\%), and 36 were managers (36.0\%) (Table1). Worker perform production works and are typically work in labor intensive positions, continuously performing repetitive tasks a produced in a team environment to mass produce a product or perform a service. A service employee is a person who provides services to other people, typically in the areas of comfort, shelter, and food. A manager is a person tasked with overseeing one or more employees or departments to ensure that employees or departments carry out assigned duties as required.

There was a statistically significant difference in physical stamina between the pre-test readings and those after the undertaking the exercise program (Table 2). After execution of the exercise program, there was no significant difference
Table 2. Physical stamina changes due to implementation of the exercise program

\begin{tabular}{lcc}
\hline & Pre-test & Post-test \\
\hline Physical stamina test & $75.03 \pm 6.15$ & $77.01 \pm 5.65^{* *}$ \\
\hline$* \mathrm{p}<0.05,{ }^{* *} \mathrm{p}<0.01$ & &
\end{tabular}

Table 3. Physical stamina changes after implementation of the exercise program by gender

\begin{tabular}{ccc}
\hline & Gender & $\begin{array}{c}\text { Pre- and Post-test } \\
\text { score change } \\
\text { Mean } \pm \text { SD }\end{array}$ \\
\hline Physical stamina change & Male & $2.12 \pm 4.47$ \\
Female & $2.47 \pm 3.52$ \\
\hline * $<0.05, * * 0<0.01$ & &
\end{tabular}

$* \mathrm{p}<0.05,{ }^{* *} \mathrm{p}<0.01$

Table 4. Physical stamina changes due to the exercise program based on age

\begin{tabular}{ccc}
\hline Age & $\begin{array}{c}\text { Pre- and Post-test } \\
\text { score change } \\
\text { Mean } \pm \text { SD }\end{array}$ \\
\hline Physical stamina change & Below 45 & $1.66 \pm 3.77$ \\
45 and above & $2.86 \pm 4.35$ \\
\hline
\end{tabular}

$* \mathrm{p}<0.05, * * \mathrm{p}<0.01$

in the change in physical stamina between genders (Table 3). When the subjects were divided into two groups based on age with 45 years of age as the divider, the physical stamina changes after implementation of the exercise program did not display any statistical difference (Table 4).

After the exercise program, the changes in WAI scores showed a statistically significant difference. It can be seen here that implementation of the exercise program did improve the WAI of subjects in this study (Table 5). There was also no significant difference in WAI score changes between genders after the exercise program (Table 6). Furthermore, there was no significant difference in the change in WAI scores after implementation of exercise program between the two groups of workers divided by age with 45 years of age as the divider (Table 7).

As a result, there appeared to be a positive correlation $(p<0.05)$ between the change in WAI scores and the change in physical stamina readings.

\section{DISCUSSION}

This aim of this study was to understand if physical strength of workers contributes to work ability improvement and health promotion of workers and if these things could lead to improvement of productivity in workplace. According to the results of the present study, there was no any difference by age and sex, but there was a difference by profession.

As workers age, their physical and metal working 
Table 5. Changes in WAI due to the exercise program

\begin{tabular}{ccc}
\hline & $\begin{array}{c}\text { Pre-test } \\
\text { Mean } \pm \text { SD }\end{array}$ & $\begin{array}{c}\text { Post-test } \\
\text { Mean } \pm \text { SD }\end{array}$ \\
\hline WAI & $40.17 \pm 4.13$ & $41.52 \pm 4.55^{* *}$ \\
\hline$* \mathrm{p}<0.05, * * \mathrm{p}<0.01$ &
\end{tabular}

Table 6. Changes in WAI after implementation of the exercise program by gender

\begin{tabular}{ccc}
\hline & Gender & $\begin{array}{c}\text { Pre- and Post-test score change } \\
\text { Mean } \pm \text { SD }\end{array}$ \\
& Male & $0.98 \pm 2.37$ \\
\multirow{2}{*}{ WAI } & Female & $1.90 \pm 3.66$ \\
\hline
\end{tabular}

$* \mathrm{p}<0.05, * * \mathrm{p}<0.01$

Table 7. Changes in WAI scores after implementation of the exercise program based on age

\begin{tabular}{ccc}
\hline \multirow{2}{*}{ Age } & $\begin{array}{c}\text { Pre- and Post-test score change } \\
\text { Mean } \pm \text { SD }\end{array}$ \\
\hline \multirow{2}{*}{ WAI $\quad$ Below 45 } & $1.15 \pm 2.24$ \\
& 45 and above & $1.18 \pm 3.56$ \\
\hline$* \mathrm{p}<0.05, * * \mathrm{p}<0.01$ &
\end{tabular}

abilities decrease, but works remains the same. This cause work productivity to decrease and the personal injury rate as worker age including musculoskeletal system disorders, to sharply increase for youth and adult groups, and the average number of personal injury cases and lost days of work tend to increase ${ }^{11)}$. While there are many articles indicating that work ability gradually decrease as workers age in many countries of Europe, in the case of Asian countries, many articles that ages do not affect work ability have been published ${ }^{7}$ 12-17). The result concerning work ability according to age in the present study also revealed that age does not affect work ability, as reported in other Asian studies.

According to the study by Ilmarinen et al. (1999), improving work ability enables not only improvement of work ability but also promotes health and productivity ${ }^{18)}$. Also, in the study of Jorien et al. (2011), physical activities such as aerobic exercise were proved to improve work capabilities and to decrease the number of days workers take as sick leave ${ }^{19)}$. This corresponds to the relationship between physical abilities and work capabilities shown in this study.

Work abilities, which were introduced in 1990 by the Finland Industrial Health Research Center, are known to be affected by not only physical factors of human resources but also mental factors. Owing to aging of the industrial environment, improvement of productivity with age and efficiency through implementation of measures to improve the quality of work of workers over 45 years of age and active prevention programs for physical and mental health are likely to be important tasks.
As mentioned above, the Work Ability Index (WAI) is used as a general tool for health management in Europe (Finland, etc.). While overall industrial health projects for workers are actively carried out like this, it is hard to carry out this subject thorough learning organizations when there is not any study related with it in Korea. However, there are many limitations in trying to generalize the finding of the present study, and further continuous studies are needed.

In particular, study of physical and overall work abilities of workers in consideration of characteristics such as age, sex and job group (by process) should be continued and Korean-type work health promotion techniques based on these study tasks should be developed urgently. We expect this study will provide momentum and be used as a basic material for establishing future industrial health policy.

\section{REFERENCES}

1) Ilmarinen J: Aging, work and health. In: Snel J, Cremer R editors. Work and aging: a European perspective. London: Taylor \&Francis, 1994, pp 47-63.

2) Chiu MC, Wang MJ, $\mathrm{Lu} \mathrm{CW}$, et al.: Evaluating work ability and quality of life for clinical nursed in Taiwan. Nurs Outlook, 2007, 55: 318-326. [Medline] [CrossRef]

3) Ilmarinen J, Rantanen J: Promotion of work ability during aging. Am J Ind Med, 1999, 36: 21-23. [CrossRef]

4) Ilmarinen J, Costa G: Aging of the working population in the European Union. Med Lav, 2000, 91: 279-295. [Medline]

5) Ilmarine J: Ageing workers in the European Union: status and promotion of work ability, employability, and employment. Helsinki: Finish Institute of Occupational Health, Ministry of Social Affairs and Health, Ministry of Labour, 1999.

6) Costa G, Sartori S, Bertoldo B, et al.: Work ability in health care worker. Int Congr Ser, 2005, 1280: 264-269. [CrossRef]

7) Tuomi K, Huuhtanen P, Nykyri E, et al.: Promotion of work ability, the quality of work and retirement. Occup Med (Lond), 2001, 51: 318-324. [Medline] [CrossRef]

8) Weyerer S, Kupfer B: Physical exercise and psychological health. Sports Med, 1994, 17: 108-116. [Medline] [CrossRef]

9) Garrett NA, Brasure M, Schmitz KH, et al.: Physical inactivity: direct cost to a health plan. Am J Prev Med, 2004, 27: 304-309. [Medline] [CrossRef]

10) Dishman RK, Oldenburg B, O'Neal H, et al.: Shephard RJ. Worksite physical activityinterventions. Am J Prev Med, 1998, 15: 344-361. [Medline] [CrossRef]

11) Brief AP, Schule RS, Van SM: Managing Job Stress. Boston: Little, Brown, 1981.

12) Ilmarinen J, Tuomi K, Klockars M: Changes in the work ability ofactive employees over an 11-year period. Scand J Work Environ Health, 1997, 23: 49-57. [Medline]

13) Liira J, Matikainen E, Leino-Arjas P: A work ability of middle-aged Finnish construction workers-a follow-up study in 1991-1995. Int J Ind Ergon, 2000, 25: 477-481. [CrossRef]

14) Hasselhorn HM, Müller BH, Freude G, et al.: The Work Ability Index (WAI)-establishment of a German WAI-network. Int Congr Ser, 2005, 1280: 292-295. [CrossRef]

15) Duong KV, Nguyen NN, Ta QB, et al.: Primary study on work ability of Vietnamese workers. International Commission on Occupational Health, 2007.

16) Chumchai $P$, Silpasuwan $P$, Viwatwongkasem $C$, et al.: Work ability among truck drivers in Thailand. International Commission on Occupational Health, 2007.

17) Kumashiro M, Yamamoto K, Shirane K: WAI and job stress, five years of follow-up research. International Ergonomics Association, 2006.

18) Ilmarinen J, Louhevaara $V$, editors.: FinnAge-respect for the aging: action programme to promote health, work abilty and well-being of aging workers in 1990-96, people and work, research reports 26. Helsinki: Finnish Institute of Occupational Health, 1999.

19) Jorien ES, Karin IP, Maartke MV, et al.: The role of work ability in the relationship between aerobic capacity and sick leave: a mediation analysis. Occup Environ Med, 2011, 86: 753-758. 